\title{
MAPEAMENTO MORFOLÓGICO DE DETALHE: EXPERIÊNCIAS PARA A INTEGRAÇÃO ENTRE TÉCNICAS DE FOTOINTERPRETAÇÃO E SISTEMAS DE INFORMAÇÕES GEOGRÁFICAS NO MUNICÍPIO DE SALESÓPOLIS-SP
}

\author{
Pablo Luiz Maia Nepomuceno ${ }^{1}$ \\ Ailton Luchiari ${ }^{2}$
}

Resumo: O mapeamento morfológico consiste numa das etapas mais importantes do mapeamento geomorfológico, ele incorpora aspectos da morfografia, ou seja: do mapeamento qualitativo das formas que compõem um relevo; e da morfometria, ou seja: do mapeamento das características quantitativas do relevo (FLORENZANO, 2008). Tais mapeamentos são tradicionalmente realizados a partir da utilização de técnicas de fotointerpretação estereoscópica, sobre fotografias aéreas verticais, combinadas com técnicas de obtenção de variáveis morfométricas por interpretação analógica de cartas topográficas. No entanto, o crescente avanço das técnicas de manipulação de dados topográficos por meio dos Sistemas de Informações Geográficas-SIG vem disponibilizando novos recursos para a obtenção de variáveis morfométricas, o que tem ampliado a precisão e eficiência destes mapeamentos, bem como as suas possibilidades de aplicação. Nesse sentido, a presente pesquisa se propôs a realizar o mapeamento morfológico em escala de detalhe (1:7.500) da área onde está assentado o sítio urbano atual do Município de Salesópolis-SP; a partir da combinação entre variáveis morfométricas, obtidas através de técnicas de Sistemas de Informações Geográficas, com variáveis morfográficas do relevo, obtidas com a utilização de técnicas de fotointerpretação tradicionais, de tal maneira que permitisse a classificação morfológica da área por meio do uso combinado destas técnicas.

Palavras Chave: Geomorfologia, Sistemas de Informações Geográficas, Mapeamento Morfológico, Mapeamento Morfométrico, Fotointerpretação.

\section{Morphological mapping detail: Experiments for integration between photointerpretation techniques and Geographic Information Systems in Salesópolis-SP}

\begin{abstract}
The morphological mapping is one of the most important stages of geomorphological mapping. It incorporates aspects of morphography (the qualitative mapping of forms that make up a landform); and morphometry (the mapping of quantitative traits a landform). Such mappings are traditionally made from the use of image interpretation techniques on stereoscopic aerial photographs combined with techniques to obtain morphometric variables by analogical interpretation of topographic maps (FLORENZANO, 2008). However, the increasing advancement of technical data manipulation topographic, by means of GIS - Geographic Information Systems, have been offering new resources for obtaining morphometric variables, which have increased the accuracy and efficiency of this mapping as well as their application possibilities. In this sense, the present search aimed to perform the morphological mapping in detail scale (1:7.500) from where it sat urban site of the current city of Salesópolis - SP; from the combination of morphometric
\end{abstract}

\footnotetext{
${ }^{1}$ LASERE\Departamento de Geografia. Faculdade de Filosofia Letras e Ciências Humanas. USP.

${ }^{2}$ LASERE\Departamento de Geografia. Faculdade de Filosofia Letras e Ciências Humanas. USP.
} 
variables obtained with techniques of Geographic Information Systems, with varying morfographyc of landform, obtained with the use of traditional techniques of photo interpretation in such a way that allowed the morphological classification of the area through the combined use of such techniques.

Keywords: Geomorphology, Geographic Information Systems, Morphological mapping, Mapping Morphometric, Photointerpretation.

\section{INTRODUÇÃO}

O Município de Salesópolis está localizado no extremo leste da Região Metropolitanta de São Paulo e a sua área urbana está assentada nos contrafortes da Serra do Mar do Planalto Atlântico do leste paulista, que possui características de um relevo fortemente dissecado com grandes declividades e alta densidade de drenagens em fundos de vale fortemente entalhados (ROSS \& MOROZ, 1997). Tais características se impõem como barreiras á ocupação urbana, muitas vezes condicionando o seu desenvolvimento em determinados setores e limitando em outros. De início a sua ocupação de carácter urbano se deu ao longo das estreitas planícies do Rio Paraitinga e do Córrego Padre Manoel, próximo a sua foz na margem esquerda do Rio Paraitinga, isso desde os princípios de século XIX, e assim se manteve sem grandes alterações até o fim do século passado. No início da primeira década do século XXI a cidade ganhou o status de Estância Turística o que somado à proximidade com São Paulo (cerca de $100 \mathrm{~km}$ ) e os atrativos naturais disponíveis (cachoeiras, trilhas em mata preservada, Parque Estaduais e Municipais, Casarões do período imperial, entre outros) vem fazendo com que a cidade sofra um crescente processo de especulação imobiliária e crescimento urbano, principalmente nas imediações do perímetro urbano do Município. Essas novas ocupações geralmente são constituídas por casas de veraneio que gradualmente vêm avançando sobre as encostas dos morros situados nas adjacências das planícies tradicionalmente ocupadas, do que consiste no núcleo central do Município.

Tendo em vista que o mapeamento Morfológico consiste numa etapa indispensável das pesquisas geomorfológicas, bem como das avaliações geotécnicas; o presente trabalho se propõe a produzir um mapa Morfológico em escala de detalhe da área central Município de Salesópolis-SP, onde está assentado o seu sítio urbano atual, para que dessa maneira possa subsidiar políticas públicas de planejamento da expansão urbana adequada do município em relação as características do relevo local. 
No entanto, mais do que gerar informações capazes de subsidiar o planejamento da expansão urbana de Salesópolis, o objetivo principal do trabalho é o de contribuir para o fomento de novas técnicas relativas à utilização integrada de dados morfométricos, obtidos a partir do processamento de dados topográficos em ambiente SIG, com dados provenientes da interpretação estereoscópica de fotografias aéreas verticais, voltadas ao mapeamento de Morfológico em escala de detalhe; tendo em vista que essa integração é ainda pouco explorada no país, principalmente no que se refere aos estudos em áreas urbanas e periurbanas (THIESEN \& OLIVEIRA, 2010).

\section{OBJETIVO}

Produzir um mapa Morfológico em escala de detalhe (1:7.500) da área central Município de Salesópolis-SP onde está assentado o seu sítio urbano atual, a partir da combinação de variáveis morfométricas com variáveis morfográficas do relevo, de tal maneira que possibilite a identificação, a delimitação e a classificação morfológica da área com base em 3 (três) propostas de legendas diferentes.

\section{MATERIAIS UTILIZADOS}

Vetores de curvas de nível e pontos cotados, contendo atributos altimétricos, e vetores de rede de drenagem, todos provenientes de restituição aerofotogramétrica em escala 1:2.000 encomendada pela SABESP (Companhia de Saneamento Básico do Estado de São Paulo) no ano de 2004; arquivos matriciais de ortofotos do ano de 2004 na escala 1:2500 para a área de abrangência do objeto de estudo; software de SIG ArcGis 9.3.1 da ESRI.

\section{MÉTODOS}

Antes de se iniciar qualquer tipo de mapeamento deve se definir quais os objetos e/ou fenômenos que são de interesse para serem mapeados, ou seja: o próprio objetivo do mapeamento. Tal questionamento está diretamente relacionado à escolha da legenda a ser utilizada durante o trabalho, isso não apenas no que se refere à representação adequada destes objetos e 
fenômenos, mas também a própria realização do trabalho científico de mapeamento em si, já que é a legenda que norteia todo o processo de análise científica para a identificação, delimitação/localização e classificação dos temas a serem mapeados, tendo em vista que todos eles têm de estar contidos e representados na legenda do mapa.

Na cartografia morfológica de detalhe existem várias propostas de legendas que se diferenciam tanto nos objetos e fenômenos a ser mapeados quanto na própria maneira de representação dos mesmos. Para a execução deste trabalho foram adotadas três diferentes legendas que consistem em três diferentes formas de abordagem da cartografia geomorfológica, a saber: a proposta dos "tipos e formas de vertentes" ou "setores das vertentes de cada uma das formas do relevo" desenvolvida por Ross (1992), a proposta de mapeamento das "Feições Mínimas" ou "Unidades Elementares do Relevo" (COLÂNGELO, 1996) e a proposta das feições morfológicas do relevo colocadas por Tricart (1972) para a padronização da legenda geomorfológica de detalhe da França. Segundo Ross (1992) o mapeamento geomorfológico na escala de detalhe deve representar os tipos de vertentes ou setores das vertentes de cada uma das formas do relevo, o que corresponde ao $5^{\circ}$ Táxon na taxonomia proposta pelo próprio autor. Dessa maneira, cada tipologia de forma de uma vertente é geneticamente distinta; cada um dos setores dessa vertente pode apresentar características geométricas, genéticas e dinâmicas também distintas. Dessa maneira Ross (1992) observa que as representações desse táxon são possíveis apenas em escalas grandes, como 1:25.000 ou maiores. Dentre as principais características geométricas das formas das vertentes destacam-se: vertente escarpada, convexa, côncava e retilínea (ROSS, 1992).

De maneira semelhante, Colângelo (1996) define que o mapa geomorfológico de detalhe deve representar as unidades elementares do relevo, ou "feições mínimas", que consistem em feições decorrentes da combinação entre as três formas elementares do relevo nas suas projeções ortogonais em perfil e em planta, o que determina a possibilidade de 9 (nove) feições específicas do relevo. Ainda de acordo com o autor, estas 9 (nove) formas também condicionam o comportamento hidrológico de superfície, permitindo a classificação deste comportamento hidrológico em 9 (nove) tipos de fluxo resultante ou ainda em 3 (três) domínios de fluxo, conforme demonstrado na tabela 1. 


\begin{tabular}{|c|c|c|c|c|}
\hline \multicolumn{5}{|c|}{ Tabela 1 - Classificação do Comportamento Hidrológico de Superfície nas 9 Formas possíveis: } \\
\hline FM & Perfil & Planta & Fluxo Resultante & Domínio \\
\hline 1 & CV & CV & Hiperdispersor & Dispersão \\
\hline 2 & CV & R & Mesodispersor Longitudinal & \\
\hline 3 & CV & CC & Hesodispersor Radial & Transição \\
\hline 5 & R & CV & Transição ou Neutro & \\
\hline 6 & R & R & Mesoconcentrador Radial & Concentração \\
\hline 7 & CC & CV & Hipoconcentrador & Mesoconcentrador Long. \\
\hline 9 & CC & CC & Hiperconcentrador & C \\
\hline
\end{tabular}

De acordo com Florenzano (2008) compõem o objeto de estudo da Geomorfologia as variáveis referentes à morfologia, morfogênese, morfodinâmica e morfocronologia. De acordo ainda com a autora à "morfologia", objetivo último de mapeamento deste trabalho, engloba a morfografia, que é a descrição qualitativa das formas do relevo, e a morfometria, que é a caracterização do relevo por meio de variáveis morfométricas, também denominadas índices morfométricos (FLORENZANO, 2008), e é essa perspectiva que norteou o objetivo de mapeamento morfológico da presente pesquisa.

Porém, para isso devem ser utilizadas diferentes técnicas capazes de subsidiar a correta identificação das feições e características morfológicas do relevo, dentre as quais se destacam a fotointerpretação estereoscópica de fotografias aéreas verticais, a execução de trabalhos de campo, e a análise de dados morfométricos, seja por meio da interpretação de cartas topográficas ou da manipulação e do processamento destas cartas em ambiente de Sistemas de Informações Geográficas.

A fotointerpretação consiste basicamente na técnica voltada à análise qualitativa dos objetos presentes nas fotografias aéreas, sendo analisados determinados elementos de reconhecimento, como: tonalidade, cor, forma, tamanho, textura, padrão e sombra; com o objetivo de identificar determinados objetos de interesse como as redes de drenagem, traçados de estradas, categorias de uso da terra, formas de vertentes, dentre outros. Em outras palavras, podemos definir a 
fotointerpretação como o ato de examinar imagens com o fim de identificar objetos, áreas ou fenômenos e determinar o seu significado (SAMPAIO, 2007).

Para tanto o fotointerprete pode se utilizar de equipamentos capazes de fornecer visualizações em terceira dimensão da superfície terrestre, representada em fotografias aéreas verticais, por meio da visualização simultânea de uma mesma superfície sobre dois ângulos diferentes, o que é denominado por estereoscopia. Para fornecer esta percepção tridimensional com fotografias aéreas verticais, são utilizados os chamados: estereoscópios. Estereoscópios são aparelhos que permitem que os olhos trabalhem separadamente, com linhas de visão paralelas. Assim, é possível que uma área ou o objeto em comum em duas fotografias aéreas subsequentes numa mesma linha de voo, sejam visualizados nas duas fotografias simultaneamente, com um olho em cada fotografia, criando a percepção da profundidade da superfície do terreno e dos objetos que nele se encontram. De acordo com Rosa (2009), existem dois tipos fundamentais de estereoscópios: o de refração ou de lente (também chamados de estereoscópio de bolso) e o estereoscópio de reflexão ou de espelho.

Sejam quais forem os instrumentos utilizados no processo, tais técnicas são de apoio fundamental ao mapeamento morfológico, pois é através delas que é possível a obtenção de diversas informações a respeito das formas da superfície (concavidades, convexidades, desníveis topográficos, limites de compartimentos, entre outros.), o que necessariamente devem ser conferidas e enriquecidas pelo controle de campo.

Além das técnicas de fotointerpretação, o recente avanço e popularização, principalmente nas três últimas décadas, de sistemas computacionais destinados à importação, armazenamento, manipulação e representação de dados georreferenciados acerca de objetos e fenômenos que se manifestam na superfície da terrestre, os SIGs; vêm oferecendo um conjunto cada vez maior de recursos designados ao tratamento e análise de dados topográficos, capazes de fornecer novas informações geomorfométricas que podem ser utilizados no desenvolvimento de inúmeros estudos acerca da constituição e dinâmica da paisagem, incluindo-se os mapeamentos morfológicos e geomorfológicos.

De acordo com Doornkamp \& King (1971) os estudos envolvendo dados topográficos desenvolvidos a partir da segunda metade do século XX se voltaram à caracterização de unidades da paisagem com base em variáveis morfológicas, que são estreitamente ligadas a feições geométricas da superfície analisada. 
Tais técnicas são denominadas de métodos paramétricos e fornecem uma base objetiva $\mathrm{e}$ uniforme para a identificação de sistemas terrestres (FLORENZANO, 2008); segundo Dent \& Young (1981) os métodos paramétricos de tratamento de dados topográficos em ambiente SIG se ainda não podiam fornecer informações acerca da constituição da superfície terrestre com a mesma qualidade dos métodos tradicionais até meados da década de 1980, eles já podiam, pelo menos, ser utilizados como informações auxiliares à interpretação e, portanto, capazes de enriquecer o processo analítico atribuindo maior objetividade e diminuindo tempo e custos operacionais.

É nessa perspectiva que o trabalho aqui apresentado visa realizar uma integração entre técnicas de fotointerpretação com técnicas computacionais de extração de dados morfométricos para a identificação, classificação e mapeamento das feições morfológicas do relevo.

\section{Procedimentos Técnicos}

1) Geração de Modelo Digital de Terreno (MDT) por interpolação dos vetores de pontos cotados, curvas de nível e hidrografia e conversão dos mesmos em grades regulares de informações altimétricas com resolução espacial horizontal e vertical de 1 (um) metro. Tal procedimento foi realizado através do uso do aplicativo topo to raster do módulo 3D Analyst do software de SIG ArcGIS 9.3.1 da Esri; que consiste na aplicação do interpolador ANUDEM desenvolvido por Hutchinson $(1998,1999)$. Essa técnica de interpolação foi desenhada com o objetivo específico de converter dados vetoriais em modelos hidrológicos de elevação de terreno exatos. O método se utiliza da eficiência computacional da interpolação local, como ponderação do inverso da distância, sem perder a continuidade superficial dos métodos global de interpolação, como Krigagem e spline. O êxito dessa técnica se dá por permitir que arquivos, como curvas de níveis, cursos de rios e delimitações de bacias, possam ser utilizados durante a interpolação, diminuindo os possíveis erros que possam vir a ser acometidos pelo método. Estudos recentes de comparação de interpoladores têm apontado esta técnica como meio de obtenção de melhores resultados (LOPES et. al, 2006) (NOGUEIRA e AMARAL, 2009).

2) Geração de planos de informações derivados do MDT, tais como: Sombreamento induzido do relevo por meio da aplicação da ferramenta hillshade também presente no módulo 3D Analyst do software ArcGIS 9.3.1, que consiste na simulação em 3D (tridimensional) do MDT a partir de um 
dado azimute, ângulo de inclinação do solar e exagero vertical, que são estabelecidos arbitrariamente pelo usuário de acordo com a sua finalidade ou aspecto visual desejado. Neste caso foi atribuído um exagero vertical de duas vezes, valor semelhante ao proporcionado pela maioria dos estereoscópios de bolso; tal dado serviu tanto para orientar uma interpretação prévia das características morfológicas do objeto estudado, quanto para melhorar a acuidade visual dos objetos a serem representados, utilizando-o como pano de fundo nos mapas;

Clinografia através da aplicação da ferramenta slope também presente no módulo 3D Analyst, neste caso a declividade consiste basicamente numa relação trigonométrica entre as diferenças de altitude e distância de cada pixel em relação aos seus oito-vizinhos fornecendo informações a respeito do ângulo de inclinação da superfície em cada pixel do MDT utilizado. As faixas (classes) de declividades foram ordenadas de acordo com os limites de intervenção tecnogênicas estabelecidos por instrumentos legais ou que são tradicionalmente conhecidos, conforme exposto por de Biasi (1992), tais como: 0 a 5\% (que consiste no limite máximo para implantação de indústrias), 5 a 12\% (que consiste no limite máximo para a mecanização agrícola), (12 a 30 \% que consiste no limite máximo para a urbanização sem restrições de acordo com a Lei federal 6766 de 1979, conhecida como Lei Lehmann); 30 a 47\% (que consiste no limite máximo para o corte raso de florestas), 47 a 100\% (que consiste no limite máximo para a extração de toros) e acima de 100\% (que consistem em declividades onde não é permitida qualquer intervenção de acordo com o Código Florestal Brasileiro de 1965 revisado em 2012); Curvaturas em Planta (ou Horizontal) e em Perfil (ou Vertical) consistem basicamente no cálculo de variação da declividade no sentido horizontal (para curvaturas em planta) e no sentido vertical á superfície (para curvaturas em perfil), nos quais os valores são expressos em \% de variação da declividade dividido por metro percorrido no terreno (SAVIGEAR, 1965; YOUNG, 1964). Nesta perspectiva valores positivos na direção da jusante caracterizam-se por formas convexas significando que houve um aumento no ângulo da declividade (na direção horizontal de mesmo nível altimétrico ou paralela a superfície para o caso se curvaturas em planta, e na direção vertical ou perpendicular a superfície no caso de curvaturas em perfil), da mesma forma que valores negativos configuram em formas côncavas e valores próximos de zero, ou seja, sem variação significativa da declividade são considerados como formas retilíneas (CHRISTOFOLETTI,1980). 
3) Geração do Mapa de Feições Mínimas por intersecção dos planos de informação das curvaturas (em planta e em perfil), o que culminou nas nove formas possíveis, conforme explicitado na Tabela

1. O resultado deste procedimento pode ser observado no Mapa 1.

4) Geração do Mapa de Comportamento Hidrológico de Superfície por reclassificação das nove formas obtidas no Mapa de Feições Mínimas de acordo com os domínios a que eles correspondem (Dispersão, Transição e Concentração de fluxos hidrológicos), conforme se encontra explicitado na Tabela 1, o resultado deste procedimento consiste no Mapa 2.

5) Geração do Mapa Morfológico Preliminar por técnicas de fotointerpretação aplicadas sobre as Ortofotos sobrepostas com transparência de $40 \%$ em relação ao "Sombreamento Induzido do Relevo", a adoção de tal procedimento permitiu simular uma visão estereoscópica das ortofotos proporcionando uma sensação de visualização das mesmas em três dimensões, podendo ser entendido como uma pseudo-estereoscopia. Para a identificação e classificação morfológica da área objeto de estudo foi adotada a legenda proposta por Tricart (1972) para o mapeamento geomorfológico em escala de detalhe.

A adoção de tais procedimentos e legendas permitiu à identificação e vetorização dos seguintes elementos morfológicos: Rupturas Côncavas de Planícies Nível 1, Rupturas Côncavas de Planícies Nível 2 (terraços), Rupturas Convexas de Topos de Interflúvios, Rupturas Convexas em perfil e Côncavas em planta de Cabeceiras de Drenagem, Vales em Berço, Vales em "V", Canais Fluviais Perenes, Canais Pluviais e Fluviais intermitentes, Canais Pluviais e Fluviais intermitentes urbanizados e Canais Fluviais perenes em subsuperfície; e são exemplificados na legenda demonstrada na Tabela 2 a seguir.

Tabela 2 - Legenda do Mapa Morfológico (Mapa 3)

\begin{tabular}{|c|c|c|c|}
\hline Nome & Imagem Vertical & Imagem Oblíqua & Descrição \\
\hline $\begin{array}{c}\text { Drenagem } \\
\text { Intermitente }\end{array}$ & & & $\begin{array}{c}\text { Curso fluvial ou pluvial } \\
\text { que apresenta } \\
\text { interrupção no curso } \\
\text { hídrico pelo menos } \\
\text { durante o período de } \\
\text { estiagem }\end{array}$ \\
\hline
\end{tabular}




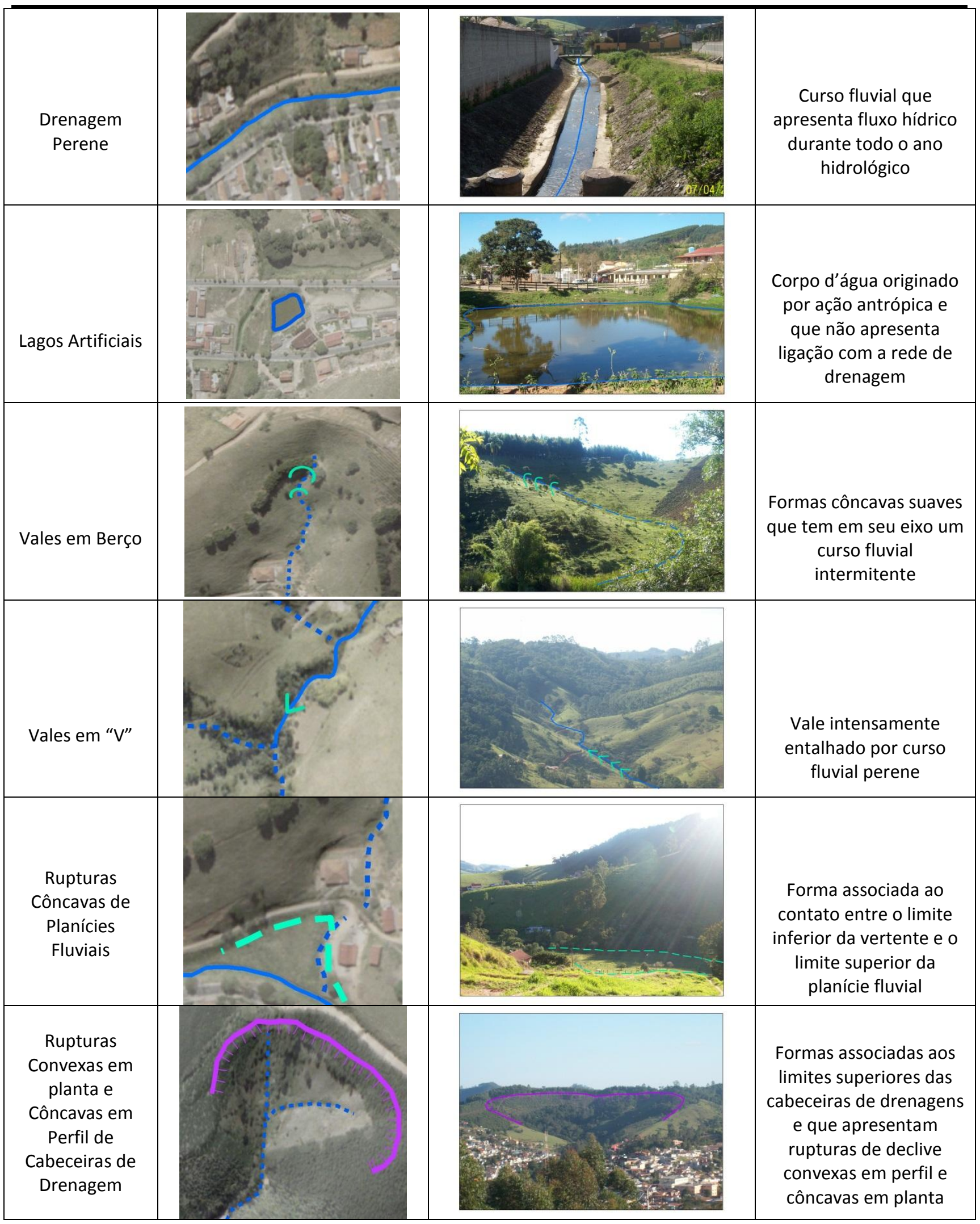




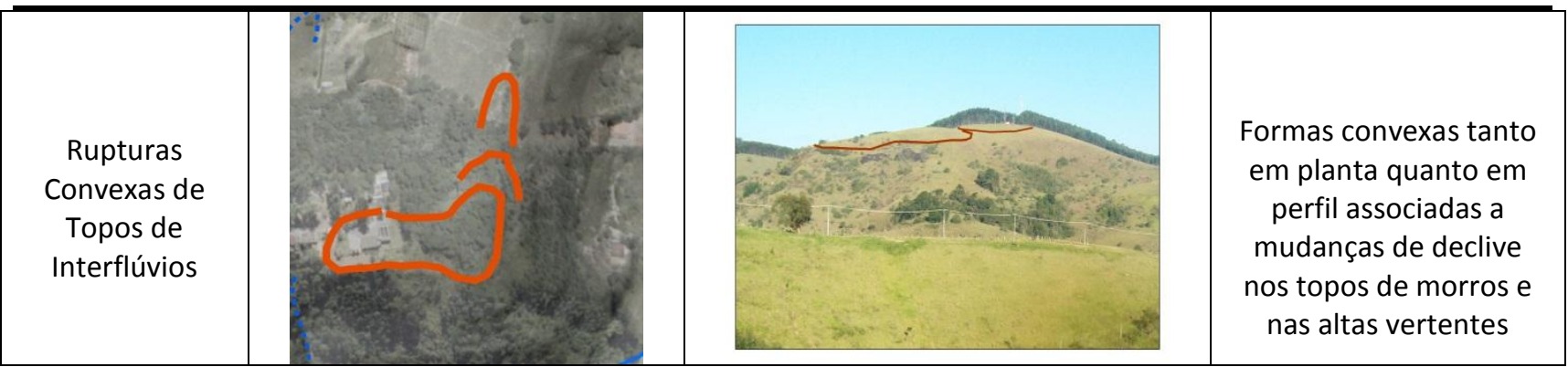

6) Conferência e Refinamento do Mapeamento Morfológico Preliminar por sobreposição e comparação dos dados gerados no mapeamento morfológico preliminar com os dados morfométricos obtidos a partir do Modelo Digital de Terreno (Curvaturas em Perfil, Curvaturas em Planta e Declividade). Nesta etapa da pesquisa as feições morfológicas restituídas preliminarmente pela fotointerpretação "pseudo-estereoscópica" das ortofotos sobrepostas ao Sombreamento Induzido do Relevo, foram analisadas em relação a cada um dos planos de informações morfométricos de tal maneira que permitiu a validação de parte das feições identificadas no mapeamento preliminar e o ajuste de dimensão e localização de outras feições que não estavam de acordo com os dados constantes nas variáveis morfométricas (clinografia e curvaturas em planta e perfil), que funcionaram como dados auxiliares ao refinamento do mapeamento morfológico preliminar, indicando necessidades de ajustes no posicionamento, orientação e dimensionamento das feições previamente identificadas. O resultado de tais procedimentos está demonstrado no Mapa 3.

7) Geração do Mapa de Compartimentação Morfológica por identificação de áreas homogêneas dos planos de informação morfométricos (Curvaturas em Perfil e Planta e Clinografia) somado às feições lineares, conferidas e refinadas no mapeamento morfológico, e ao "Comportamento Hidrológico de Superfície", derivado das "Feições Mínimas ou Unidades Elementares do Relevo". Nesta etapa foi adotada a legenda proposta por Ross (1992) no que se refere ao registro das feições geomorfológicas no $5^{\circ}$ táxon. As feições morfológicas previamente mapeadas (Rupturas Côncavas de Planícies Nível 1, Rupturas Côncavas de Planícies Nível 2 (terraços), Rupturas Convexas de Topos de Interflúvios, Rupturas Convexas em perfil e Côncavas em planta de Cabeceiras de Drenagem, Vales em Berço, Vales em "V", Canais Fluviais Perenes, Canais Pluviais e Fluviais intermitentes, Canais Pluviais e Fluviais intermitentes urbanizados e Canais Fluviais perenes em subsuperfície) por si mesmas já fornecem indicações dos limites dos compartimentos 
morfológicos baseados na proposição de Ross (1992); como por exemplo, as rupturas côncavas de planícies de nível 1 que indicam o limite do terraço de nível mais baixo da planície fluvial, as rupturas de cabeceiras de drenagem que indicam os limites superiores dos vales e anfiteatros de cabeceiras de drenagem, entre outros.

A execução de tal procedimento permitiu a identificação, classificação e vetorização de quatro compartimentos morfológicos na área objeto de estudo: Topos de Interflúvios, Vertentes Plano/Convexas (Suaves, Médias e Aguçadas), Anfiteatros e Vales Côncavos de Cabeceiras de Drenagens e Planícies Fluviais (Nível 1 e Nível 2). Para a delimitação destes compartimentos foi elaborada uma matriz de correlacionamento entre os tipos de compartimentos e as variáveis morfométricas a eles associados, conforme se encontra explicitado na Tabela 3, o que funciona como uma chave de interpretação para a identificação destes compartimentos. O resultado deste procedimento pode ser observado no Mapa 4.

Tabela 3: Chave de Interpretação Morfológica por combinação das Variáveis Morfométricas e Feições Morfológicas

\begin{tabular}{|c|c|c|c|c|c|}
\hline Compartimento & $\begin{array}{l}\text { Curvatura } \\
\text { em Perfil }\end{array}$ & $\begin{array}{c}\text { Curvatura em } \\
\text { Planta }\end{array}$ & $\begin{array}{c}\text { Comportamento Hidrológico } \\
\text { de Superfície }\end{array}$ & $\begin{array}{l}\text { Declivi } \\
\text { dade }\end{array}$ & $\begin{array}{c}\text { Forma } \\
\text { Associada }\end{array}$ \\
\hline Topos de Interflúvios & $C x$ & $C x$ & $\mathrm{Dp}$ & $<12 \%$ & Rpt TI \\
\hline Vertentes Suaves & $\mathrm{Cx} / \mathrm{PI}$ & $\mathrm{Cx} / \mathrm{PI}$ & $\mathrm{Dp} / \mathrm{Nt}$ & $<12 \%$ & \\
\hline Vertentes Médias & $\mathrm{Cx} / \mathrm{PI}$ & $\mathrm{Cx} / \mathrm{PI}$ & $\mathrm{Dp} / \mathrm{Nt}$ & $\begin{array}{l}12- \\
30 \% \\
\end{array}$ & \\
\hline Vertentes Aguçadas & $\mathrm{Cx} / \mathrm{PI}$ & $\mathrm{Cx} / \mathrm{PI}$ & $\mathrm{Dp} / \mathrm{Nt}$ & $>30 \%$ & \\
\hline $\begin{array}{c}\text { Anfiteatros e Vales de } \\
\text { Cabeceiras de Drenagens }\end{array}$ & $\mathrm{Cv} / \mathrm{PI}$ & $\mathrm{Cv} / \mathrm{PI}$ & $\mathrm{Cc}$ & $>12 \%$ & Rpt CD \\
\hline Planícies Fluviais Nível 1 & $\mathrm{PI}$ & $\mathrm{PI}$ & $\mathrm{Nt}$ & $<5 \%$ & Rpt PI N1 \\
\hline Planícies Fluviais Nível 2 & $\mathrm{Pl}$ & $\mathrm{PI}$ & $\mathrm{Nt}$ & $<12 \%$ & Rpt PI N2 \\
\hline
\end{tabular}

\section{Significado das Siglas:}

Curvaturas: $\mathrm{Cx}=$ Convexo; $\mathrm{Cv}=$ Concavo; $\mathrm{Pl}=\mathrm{Plano}$

Comportamento Hidrológico de Superfície: $\mathrm{Dp}=$ Dispersor; $\mathrm{Nt=Neutro;} \mathrm{Cc}=$ Concentrador

Forma Associada: Rpt TI = Rupturas Convexas de Topos de Interflúvios; Rpt CD = Rupturas Convexas em perfil e Côncavas em Planta de Cabeceiras de Drenagens; Rpt PI N1 = Rupturas Côncavas de Planícies Fluviais Nível 1; Rpt PI N2 = Rupturas Côncavas de Planícies Fluviais Nível 2.

A seguir é apresentada a Figura 1, que sintetiza todas as etapas e procedimentos descritos acima por meio de um fluxograma geral de trabalho. Posteriormente são apresentados os Mapas 1, 2, 3 e 4; que correspondem justamente aos resultados da execução de tais procedimentos. 


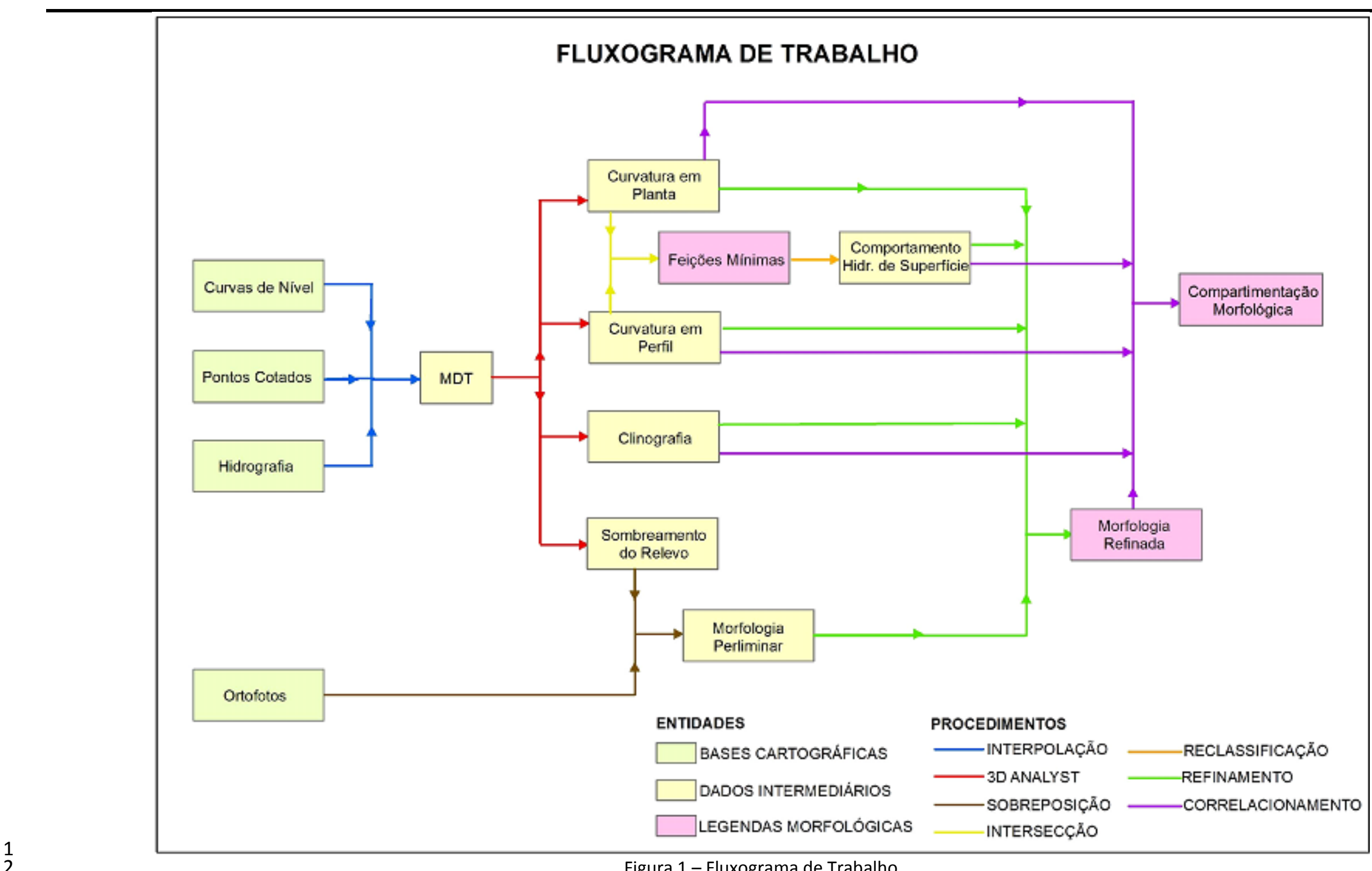

Figura 1 - Fluxograma de Trabalho 


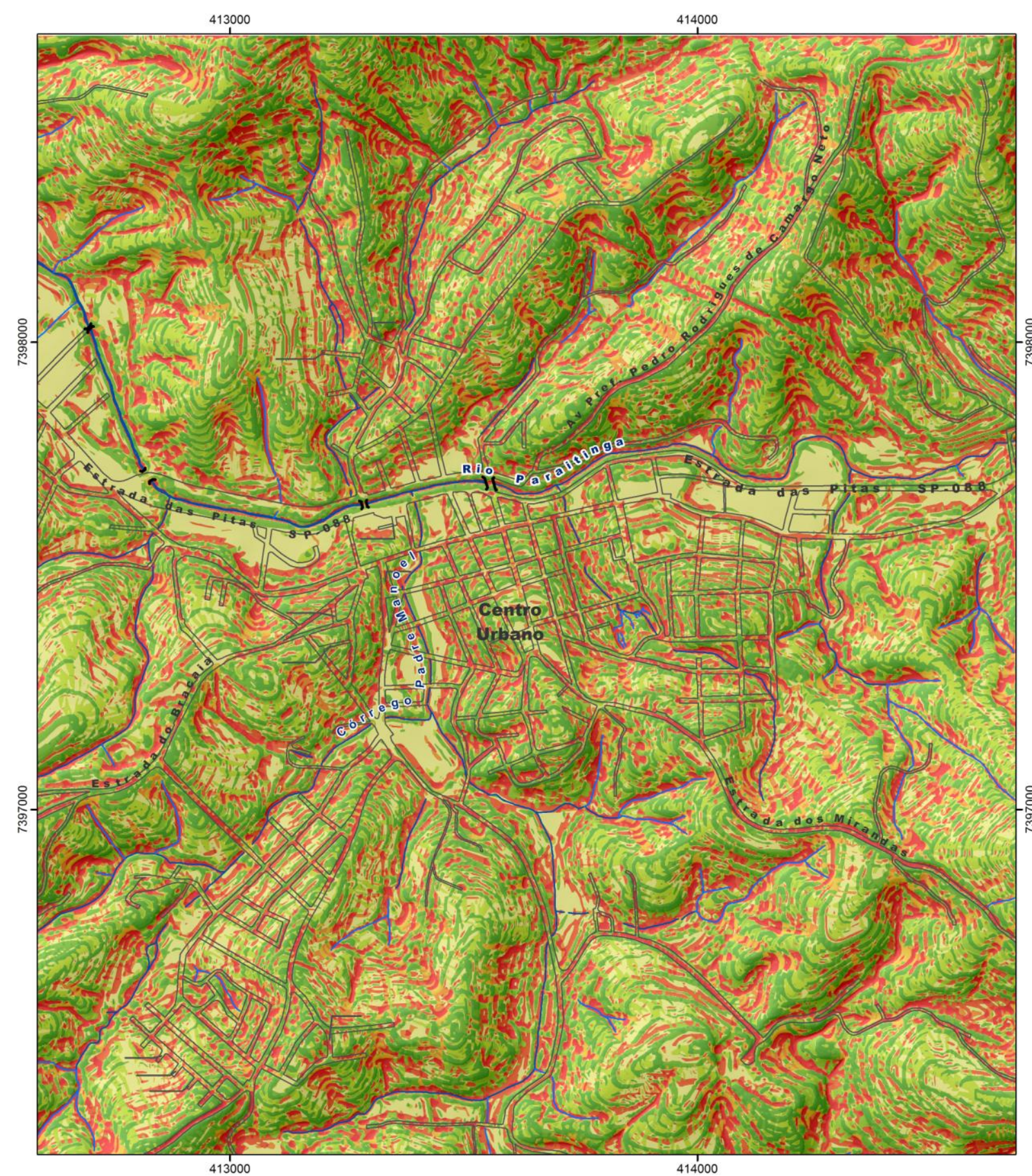

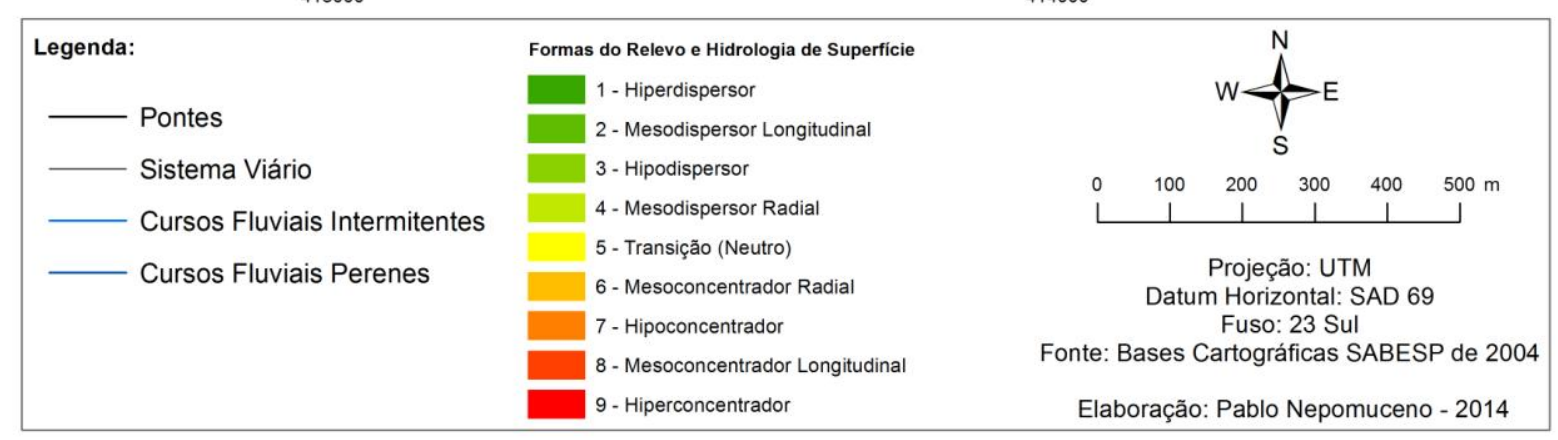

Mapa 1 - Feições Mínimas ou Unidades Elementares do Relevo e Hidrologia de Superfície 

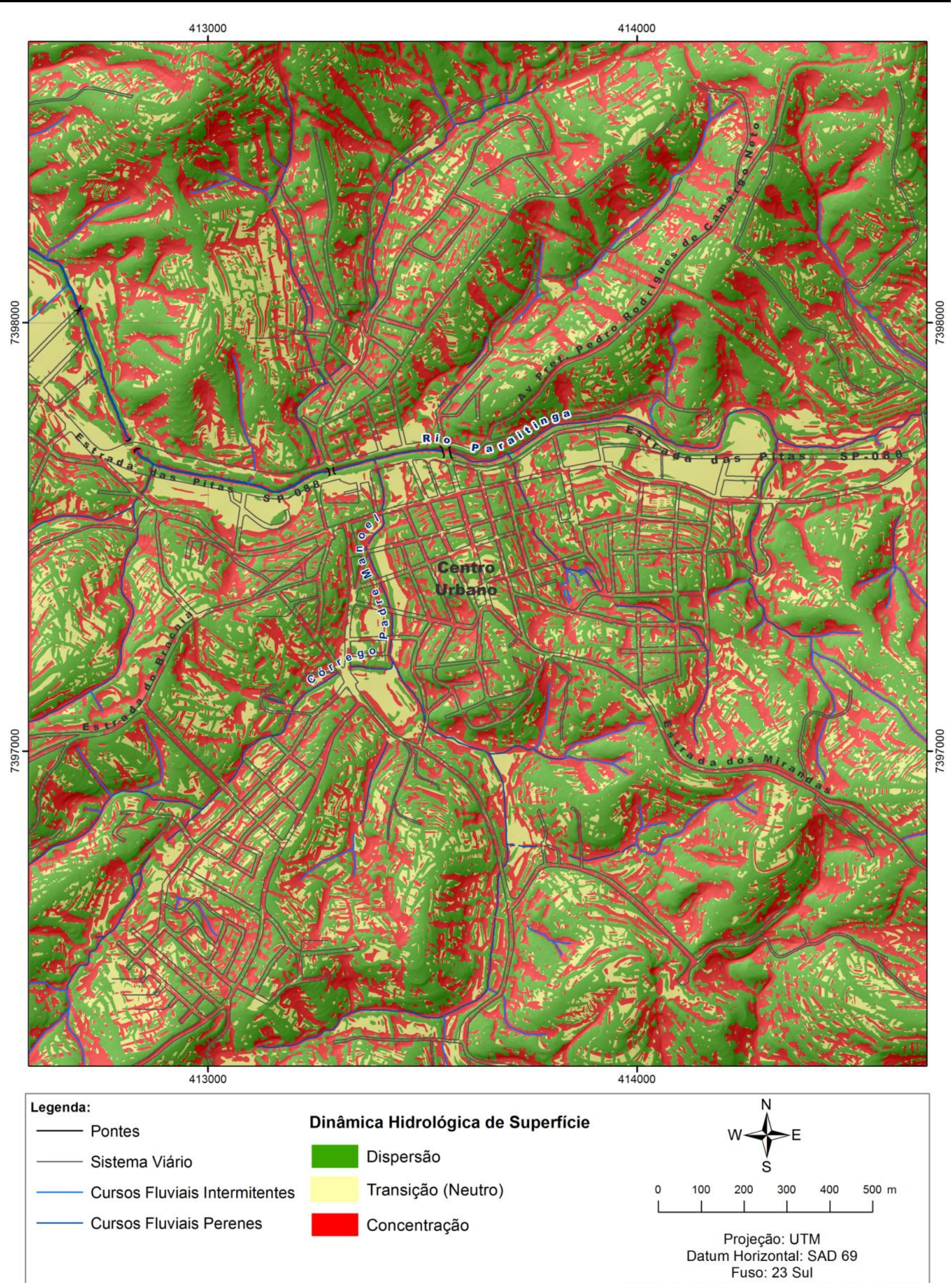

Transição (Neutro)

Concentração

Fonte: Bases Cartográficas SABESP de 2004

Elaboração: Pablo Nepomuceno - 2014

Mapa 2 - Comportamento Hidrológico de Superfície 


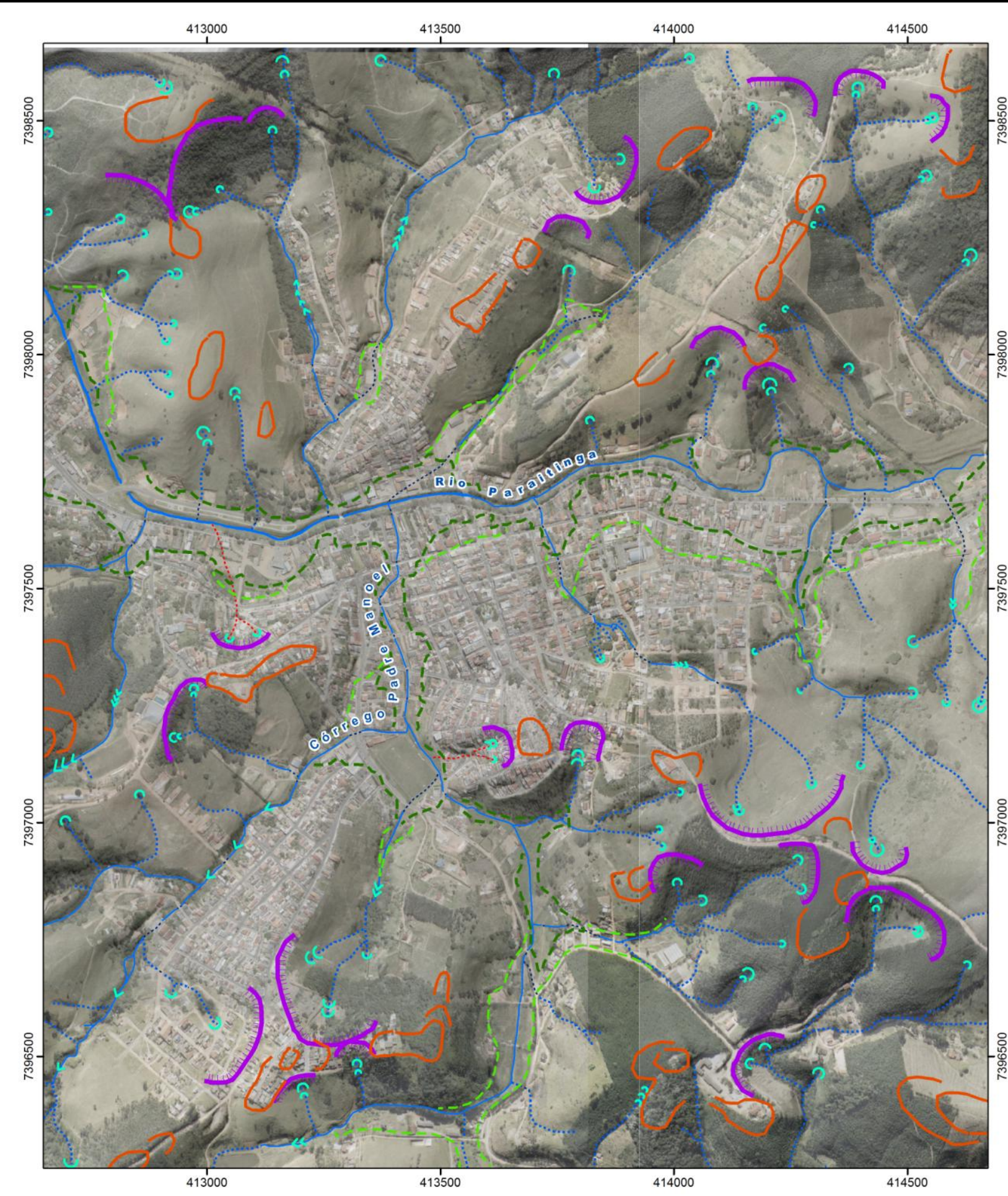

\section{Rede de Drenagem:}

....... Canais Pluviais e Fluviais Intermitentes

Canais Fluviais Perenes

........ Canais Fluviais Perenes em Subsuperficie

........ Canais Pluviais Intermitentes Urbanizados

Formas:

ก Vales em Berço de Cabeceira de Drenagem

- - - Rupturas Côncavas de Planicie Fluvial

- - - Rupturas Côncavas de Planicie Fluvial de nivel 2 - Terraços

- Rupturas Convexas deTopo de Interflúvios

Rupturas Abruptas de Cabeceira de Drenagem

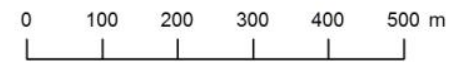

Projeção: UTM

Datum Horizontal: SAD 69

Fuso: 23 Sul

Fonte: Bases Cartográficas SABESP de 2004

Elaboração: Pablo Nepomuceno - 2014

Mapa 3 - Morfologia Refinada 


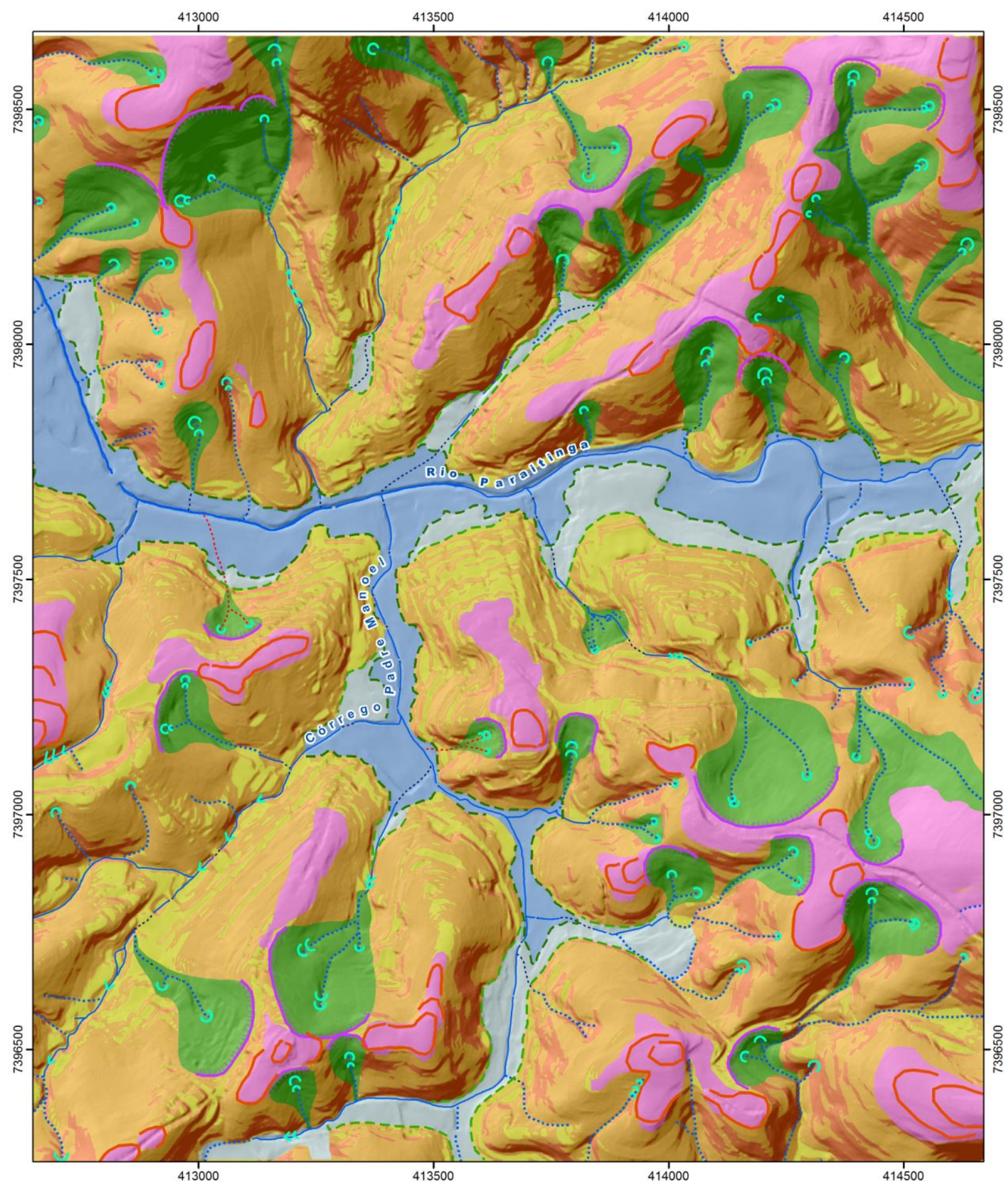

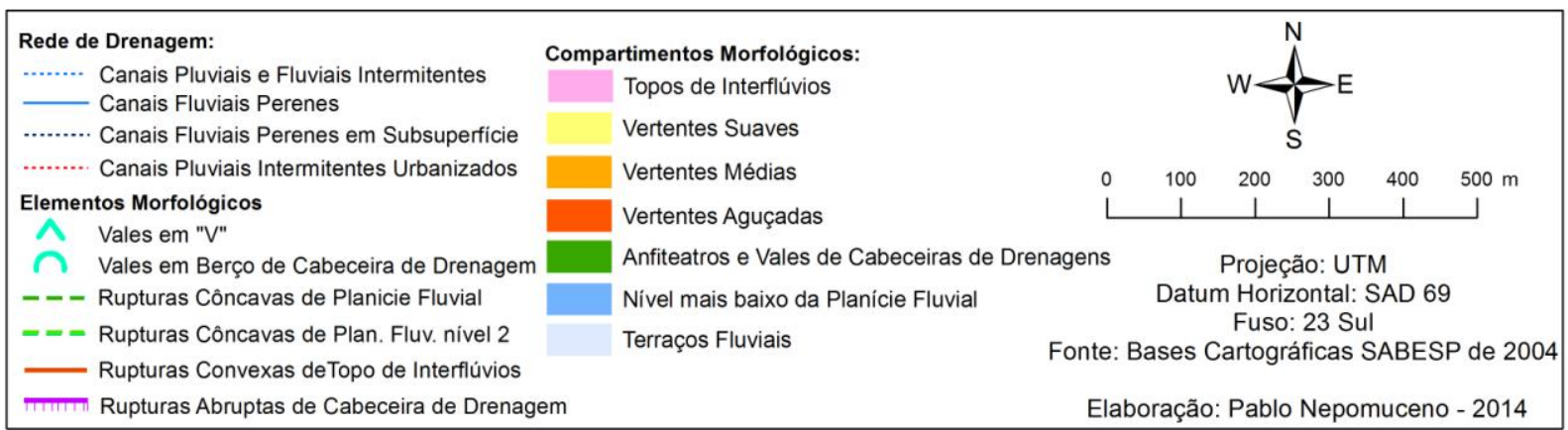

Mapa 4 - Compartimentação Morfológica 


\section{ANÁLISE DOS RESULTADOS}

As técnicas empregadas para a geração do Mapa 1 de "Feições Mínimas" ou "Unidades Elementares do Relevo" se mostraram eficientes e adequadas tendo em vista elas consistem basicamente na combinação entre os dados de curvaturas, em planta e em perfil, que são dados derivados da clinografia e que são facilmente obtidos de forma automatizada na maioria dos softwares de SIG disponíveis atualmente, o que torna a sua aplicação mais simples e com maior eficiência no tempo de execução do que em relação as técnicas convencionais baseadas exclusivamente na fotointerpretação. Além disso, o cálculo automatizado destas variáveis elimina a subjetividade no processo, pois fornecem os valores absolutos de variações da declividade (curvaturas) nas projeções em planta e em perfil, o que permite a delimitação com exatidão da área de abrangência de cada feição identificada, bem como a classificação completa da área objeto de pesquisa, constando todas as feições que nela ocorrem. Da mesma maneira acontece no Mapa 2, relativo ao "Comportamento Hidrológico de Superfície", que consiste numa reclassificação das feições mínimas, ou seja, num produto derivado do reagrupamento de classes das "feições mínimas", conforme explicitado na Tabela 1.

Quanto ao Mapa 3, de mapeamento morfológico de acordo com a legenda proposta por Tricart (1972), as variáveis morfométricas de curvaturas em planta e em perfil, bem como a clinografia e o comportamento hidrológico de superfície; foram utilizadas para a conferência, a validação e o refinamento do mapa morfológico preliminar, produzido exclusivamente a partir de técnicas de fotointerpretação. A execução de tal procedimento, da mesma maneira que no Mapa 1, se mostrou consideravelmente útil e eficiente tendo em vista que estas variáveis têm a capacidade de indicar a localização geometricamente absoluta de determinadas características do relevo que são fundamentais para a classificação morfológica de detalhe, como, por exemplo, as descontinuidades e rupturas de declive (break slope). Apesar da maior parte das feições preliminarmente mapeadas terem sido validadas através da sua análise comparativa com as variáveis morfométricas obtidas, uma parte representativa das mesmas, cerca de $20 \%$ do total de feições mapeadas, tiveram de sofrer algum ajuste de refinamento, seja por diminuição ou aumento da feição, ou mesmo por simples ajuste na posição dos mesmos. Ainda assim, no entanto, em nenhum caso estes procedimentos tiveram que se dar de maneira brusca, ou seja: apesar de cerca de $1 / 5$ das feições ter de sofrerem algum tipo de ajuste, em nenhuma delas houve 
grandes discordâncias entre o que havia sido preliminarmente mapeado e o resultado do processo de refinamento das mesmas.

Porém deve ser salientado que no caso específico deste trabalho as bases utilizadas para a execução (por fotointerpretação) do mapeamento morfológico preliminar, consistiram nas ortofotos sobrepostas em semi-transparência ao sombreamento induzido do relevo (hillshade), sendo este último derivado do mesmo Modelo Digital de Terreno que serviu de base para a extração das variáveis morfométricas utilizadas, o que naturalmente determina que haja uma concordância entre eles, visto que a origem consiste na mesma base de dados (Modelo Digital de Terreno - MDT). Além deste fato a utilização do recurso de sobreposição das ortofotos ao sombreamento do relevo, denominado aqui como sendo uma espécie de pseudo-estereoscopia, contém uma série de limitações em relação à interpretação de fotografias aéreas verticais com o uso de estereoscópios, dentre as principais delas podem ser citadas a ausência de percepção tridimensional dos objetos que estão acima da superfície do terreno (árvores, edificações, torres, etc.) e a própria constituição do dado em si, visto que o MDT utilizado possui origem nas curvas de nível e nos pontos cotados vetorizados a partir de uma restituição por interpretação estereoscópica das fotografias aéreas originais, e que dessa maneira já consistem a priori num produto de uma interpretação. Dessa maneira, a utilização da técnica neste trabalho acaba consistindo numa fotointerpretação derivada de uma base de dados produto de uma fotointerpretação anterior a esta. Portanto seria pertinente a realização dos mesmos procedimentos, mas utilizando-se de fotografias aéreas originais na confecção do mapeamento morfológico preliminar, para que produto desse procedimento fosse então confrontado com os dados passíveis de serem obtidos a partir dos MDTs.

Já o Mapa 4, de Compartimentação Morfológica, consiste num produto do correlacionamento entre as classes de todas as variáveis morfométricas geradas, conforme explicitado na tabela 3. Este procedimento visa simular alguns dos critérios utilizados pelo pesquisador durante a fotointerpretação, utilizando-se, no entanto, de combinações entre variáveis morfométricas (curvaturas, clinografia, comportamento hidrológico de superfície) e as feições morfológicas obtidas no Mapa 3, na finalidade de identificar homogeneidades no relevo, no que consiste a sua compartimentação morfológica. Estas combinações são semelhantes às relações que o fotointerprete tem que estabelecer para realizar a restituição morfológica sobre fotografias aéreas verticais com o uso de estereoscópios, como, por exemplo: a identificação de variações clinográficas abruptas e suaves indicam, em muitos casos, os limites das planícies e dos topos de 
interflúvios com as vertentes; a identificação de formas côncavas em planta e em perfil nas vertentes traduzem morfometricamente os vales em berço formadores de canais fluviais de 10 ordem; as formas convexas em perfil e em planta com baixas declividades traduzem morfometricamente os topos de interflúvios, entre outros. Nesse sentido pode se dizer que o estabelecimento de limiares de classes nas variáveis morfométricas, bem como as combinações propostas, consiste num procedimento que pretende, ao menos parcialmente, simular alguns dos critérios utilizados na fotointerpretação para o estabelecimento das mesmas categorias, podendo ser entendido como uma classificação orientada aos objetos, no caso os compartimentos morfológicos de $5^{\circ}$ táxon, a partir da combinação entre classes de variáveis morfométricas.

Para tanto foi proposta uma matriz de correlacionamento entre os tipos de compartimentos e as variáveis morfométricas a eles associados, conforme explicitado na Tabela 3, e que serve como uma chave de interpretação para a identificação destes compartimentos.

Apesar das técnicas de fotointerpretação oferecer mais recursos de análise que a combinação de dados mofométricos em ambiente de Sistemas de Informações Geográficas; da mesma maneira que foi constatado nos mapas 1, 2 e 3, a utilização desta técnica também se mostrou consideravelmente útil e eficiente, pois torna o processo mais rápido além de atribuir maior objetividade a análise. Além destes fatos deve ser salientado, que ambas as técnicas (fotointerpretação e análise combinada de dados morfométricos com SIG) não são necessariamente excludentes, pois elas podem ser utilizadas de maneira conjunta, seja utilizando as combinações como dados auxiliares a fotointerpretação, ou mesmo para a validação, conferência e o refinamento da mesma.

\section{CONCLUSÃO E CONSIDERAÇÕES FINAIS}

A popularização recente das técnicas de geoprocessamento e sistemas de informações geográficas vêm sendo acompanhadas também de uma crescente socialização e disseminação de bases de dados digitais georrefenciadas e que em muitas vezes já possuem o acesso bem menos restrito que os próprios dados analógicos originais que deram origem aos digitais, como o caso das fotografias aéreas verticais das quais derivam bases topográficas e ortofotos, materiais que foram utilizados nesta pesquisa. Por esse motivo o desenvolvimento de recursos técnicos capazes de serem utilizados para a geração de informações semelhantes às provenientes das técnicas 
tradicionais consagradas, podem oferecer importantes alternativas técnicas no que se refere à restrição de acesso às bases de dados originais.

No entanto, quanto à realização de experiências visando uma integração entre técnicas de manipulação de dados topográficos em meios computacionais com a restituição estereoscópica de fotografias aéreas verticais, é pertinente a utilização das fotografias originais para que estas fossem confrontadas com as variáveis morfométricas provenientes de MDTs de tal maneira que assim permitam a realização de avaliações mais completas acerca das possibilidades de integração entre as mesmas.

Ainda assim, a pesquisa aqui apresentada já fornece indicações de que há a possibilidade de integração entre estas técnicas e que essa integração só tende a trazer benefícios aos mapeamentos morfológicos, tanto no que se a maior eficiência no tempo de execução dos mesmos, quanto no próprio processo analítico de identificação dos elementos morfológicos objetos de interesse de mapeamento, atribuindo maior objetividade e precisão na identificação e delimitação dos mesmos.

Dessa maneira a presente pesquisa pode contribuir para fomentar e orientar a execução de novas experiências que visem o aprimoramento das técnicas de confecção de mapas morfológicos na escala de detalhe, utilizando-se de dados morfométricos, obtidos a partir do processamento de dados topográficos em ambiente SIG, combinados com dados obtidos por interpretação estereoscópica de fotografias aéreas verticais.

\section{REFERÊNCIAS BIBLIOGRÁFICAS}

CHRISTOFOLETTI, A. Geomorfologia. São Paulo: Edgard Blucher, 1980.

COLÂNGELO, A. C. Modelo de Feições Mínimas ou das Unidades Elementares do Relevo: um suporte cartográfico para mapeamentos geoecológicos In: Revista do Departamento de Geografia, São Paulo, n.10, p.29-40, 1996.

DE BIASI, M. A Carta Clinográfica: Os Métodos de Representação e a sua Confecção. Revista do Departamento de Geografia, São Paulo, n.6, p. 45-60, 1992

DENT, D; YOUNG, A. Soil survey and land evaluation. George Allen \& Unwin, London, 1981. 
DOORNKAMP, J. C; KING, C. A. M. Numerical Analysis in Geomorphology: an introduction. Edward Arnold. 1971

FLORENZANO, T. G. Sensoriamento Remoto para Geomorfologia. In: Geomorfologia: conceitos e tecnologias atuais. Ed. Oficina de Textos. São Paulo, p. 12-72, 2008.

HUTCHINSON, M.F. A new procedure for gridding elevation and stream line data with automatic removal of spurious pits. Journal of Hydrology, $n^{\circ} 106$, p. 211-232. 1989.

LOPES, E.S.S.; RIEDEL, P.S.; VIDOTTI, M.; MERINO, E.R. Análise de Modelos Numéricos de Terreno para Modelos Geomorfológicos In: VI Simpósio Internacional de Geomorfologia. Geomorfologia Tropical e Subtropical:_processos, métodos e técnicas. Gioânia-GO. 6 a 10 de Setembro de 2006. Anais...Goiânia, 2006.

ROSS, J. L. S. Registro cartográfico dos fatos geomórficos e a questão da taxonomia do relevo In: Revista do Departamento de Geografia, São Paulo, n.6, p.17-29, 1992.

ROSS, J. L. S. e MOROS, I. C. Mapa Geomorfológico do Estado de São Paulo (1:500.000) Memorial Explicativo vol. 1. São Paulo-SP. FFLCH/USP, IPT, FAPESP, 1997.

NOGUEIRA, J. D. de L.; AMARAL, R. F. do A.; Comparação entre os métodos de interpolação (Krigagem e Topo to Raster) na elaboração da batimetria na área da folha Touros - RN. In: SIMPÓSIO BRASILEIRO DE SENSORIAMENTO REMOTO, 14., 2009, Natal. Anais: INPE, 2009. p. 41174123.

SAMPAIO, E.P.M. Noções básicas de detecção Remota, fotogrametria e fotointerpretação em pedologia. Évora. 25p. 2007.

SAVIGEAR, R. A. G. A Technique of Morphological Mapping In: Anais da Associação de Geógrafos Americanos. vol 55, $n^{\circ} 3, \mathrm{p}$ 513-538. 1965.

THIESSEN, G. M. e OLIVEIRA, D. Apresentação de um Novo Método de Mapeamento Geomorfológico de Detalhe e sua Viabilidade de Aplicação como subsídio à compreensão da Paisagem Ocupada no Entorno do Reservatório Paiva Castro-Mairiporã/SP. In: Anais do XVI Encontro Nacional de Geógrafos. Porto Alegre-RS. 25 a 31 de julho de 2010. 
TRICART J. Normes pour l'établissement de la carte géomorphologique détaillée de la France: classification codée, critères d'identification et légende pratique (1:20.000, 1:25.000, 1:50.000). In: Cartographie géomorphologique. Mémoires et documents CNRS, 12, 37-105. 1972.

YOUNG, A. Slope Profile Analysis. In: Zeitschrift fur Geomorphologie. 1964.

Artigo submetido em: 23/05/2014

Artigo aceito em: 16/10/2014 